\title{
Ectopic Calcification as Discernible Manifestation in Neonates with Pseudohypoparathyroidism Type 1a
}

\author{
Masanori Adachi, ${ }^{1}$ Koji Muroya, ${ }^{1}$ Yumi Asakura, ${ }^{1}$ Yoichi Kondoh, ${ }^{2}$ \\ Jun Ishihara, ${ }^{3}$ and Tomonobu Hasegawa ${ }^{4}$ \\ ${ }^{1}$ Department of Endocrinology \& Metabolism, Clinical Research Institute, Kanagawa Children's Medical Center, \\ Yokohama 232-8555, Japan \\ ${ }^{2}$ Department of Pediatrics, Matsuyama Red Cross Hospital, Matsuyama 790-8524, Japan \\ ${ }^{3}$ Department of Pediatrics, Yokohama Municipal Citizen's Hospital, Yokohama 240-8555, Japan \\ ${ }^{4}$ Department of Pediatrics, Medical School Keio University, Tokyo 160-8582, Japan
}

Correspondence should be addressed to Masanori Adachi, madachi@mars.sannet.ne.jp

Received 23 October 2008; Accepted 9 June 2009

Recommended by Maria I. New

The diagnosis of pseudohypoparathyroidism type la (PHPla) is challenging, because both the osteodystrophy, such as brachydactyly and round face, and the symptomatic hypocalcemia usually develop beyond infancy. Although ectopic calcification may be an early sign of PHP1a, there are no systematic reviews regarding the time of its appearance. We here report on two PHP1a patients who presented with subcutaneous calcification in neonatal period.

Copyright ( 2009 Masanori Adachi et al. This is an open access article distributed under the Creative Commons Attribution License, which permits unrestricted use, distribution, and reproduction in any medium, provided the original work is properly cited.

\section{Introduction}

Pseudohypoparathyroidism type la (PHPla) is a genetic disorder caused by maternally inherited mutations of GNAS gene, which encodes the $\alpha$-subunit of the stimulatory G protein Gs $[1,2]$. Common feature in PHP1a includes Albright hereditary osteodystrophy (AHO) such as brachydactyly [3] and resistance to multiple Gs protein-coupled hormones (e.g., parathyroid hormone (PTH) and thyrotropin) [1]. Individuals with GNAS mutation on paternally inherited alleles manifest only $\mathrm{AHO}$, a variant termed pseudopseudohypoparathyroidism (pseudo-PHP) [4]. The diagnosis of PHP1a often delays due to the high variability of the age at first appearance of characteristic clinical signs [5]. Here we report on two PHPla patients with GNAS mutations, who were found to have subcutaneous calcification during neonatal period.

\section{Patient 1}

A male baby was born to nonconsanguineous Japanese parents after an uneventful pregnant course. He was delivered by Caesarian section because of bradytocia at his
36 weeks of gestation with his weight measuring $2545 \mathrm{~g}$. Asphyxia was absent. At his 3 days of age, he developed vomiting and hypothermia and was found to have hypocalcemia $(5.6 \mathrm{mg} / \mathrm{dL})$. With parenteral infusion of calcium preparation, the above symptoms resolved soon. Calcium supplementation could be withdrawn in a month. By 13 days of age, a subcutaneous nodule at right parietal region was noticed, which was thought to be an ectopic calcification by skull radiograph (Figure 1). Intracranial calcifications, particularly those in basal ganglia, were not found by CT scanning. Despite normocalcemia, his plasma level of intact PTH had been elevated continuously (55-460 pg/mL), which raised the tentative diagnosis of PHP1a. Definite diagnosis, however, was withheld because AHO phenotype was not evident at that time except for ectopic calcification. Because of hypothyroidism, thyroid hormone supplementation was initiated at his 1 year of age. Clinical reevaluation at 4 years of age revealed BMI of 26.8 (above 97th centile, according to the Japanese national survey data [6]), brachydactyly, and round face. His calcium level was still normal $(9.0 \mathrm{mg} / \mathrm{dL})$. GNAS gene analysis, under the approval of institutional review board and written informed consent from the parents, revealed the recurrent mutation [7] of 565-568delGACT 


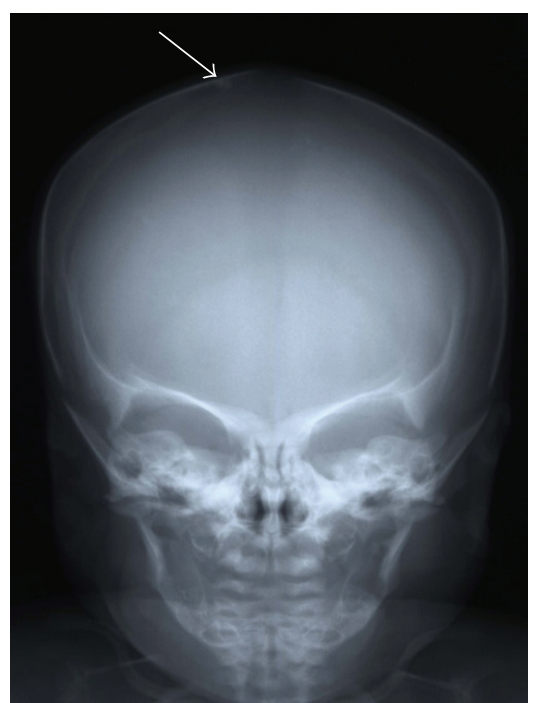

FIGURE 1: Skull radiograph of patient 1 taken on 13 days of age. White arrow indicates the calcification at right parietal region.

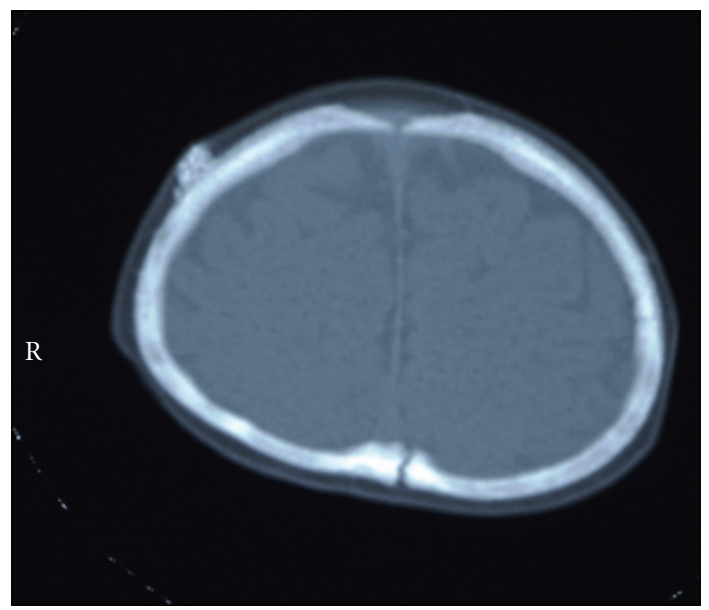

Figure 2: Skull CT image of patient 2 taken at 7 months of age. Calcification at right parietal region is evident.

(189Dfr) in heterozygous state. His mother had short stature of $145 \mathrm{~cm}$ ( $-2.5 \mathrm{SD}$ for Japanese women) and brachydactyly, which led to the presumed diagnosis of pseudo-PHP. She, however, did not request DNA analysis.

\section{Patient 2}

Patient 2 is a Japanese boy who was born at 36 weeks of gestation by Caesarian section with his weight $2892 \mathrm{~g}$. His elderly brother has ceased at day 1 because of enteric necrosis of unknown origin. His mother had been treated for threatened abortion by magnesium preparation for a month before delivery. Although asphyxia was absent, he developed respiratory distress and hypoglycemia soon after birth, both of which subsided spontaneously. At 2 days of age, hypocalcemia of ionized calcium of $0.81 \mathrm{mmol} / \mathrm{L}$ was noticed, which warranted calcium supplementation for about a month. From 9 days of age, he was treated for hypothyroidism. Around 2 weeks of age, a subcutaneous hard nodule was recognized at the right parietal region, CT scanning of which revealed it to be an ectopic calcification (Figure 2). At 6 months of age, brachydactyly and round face were noticed, which raised the suspicion of PHP1a. In addition, several hard nodules less than $10 \mathrm{~mm}$ in diameters were present in his back and thigh, which seemed subcutaneous calcifications. Although hypocalcemia had been absent, his PTH level was found to be high (134 pg/mL) after 1.5 year of age. His developmental quotient determined at his 1.5 years of age was 70. GNAS analysis of the family was performed under the approval of institutional review board and written informed consent from the parents. The patient and his mother, who is $140 \mathrm{~cm}$ tall $(-3.4 \mathrm{SD})$, had heterozygous nonsense mutation (W261X), whereas GNAS of his father, who is $160 \mathrm{~cm}$ tall $(-1.9 \mathrm{SD})$, was wild type.

\section{Discussion}

During infantile period, the clinical manifestations of PHP1a are usually subtle and, therefore, tend to be easily overlooked. In a case series study, Gelfand et al. [5] reported that brachydactyly in PHP1a was rarely noted in the first 3 years of life, although it was eventually recognized in all 12 patients. In addition, they found that symptomatic hypocalcemia developed later in childhood and that none required calcium and/or calcitriol administration in the first year of life [5].

Subcutaneous calcifications and/or ossifications have also been considered to be one of the constituents of $\mathrm{AHO}$ [3]. In a recent study [7], the average of heterotopic ossifications in 12 patients with PHP1a who attended orthopedic clinic was reported to be 10 in number, and no specific tendency was observed regarding the location of ossifications. Gelfand et al. [5] found that ectopic calcifications, next to hypothyroidism, were the second most referral reason in infants with PHP1a. However, detailed evaluation regarding the onset of ectopic calcifications has not been made, and the early onset of ectopic calcifications with AHO has been only anecdotally described $[8,9]$.

In our patients, subcutaneous calcifications were noticed no later than 2 weeks of age, and they might be already present shortly after birth. As long as we could search in literature, they may be the first cases of molecularly proven PHP1a who developed neonatal-onset subcutaneous calcifications. If this manifestation was paid more attention, it might lead to earlier diagnosis, especially in patient 2. Thus, pediatricians and neonatologists should keep in mind that ectopic calcifications may be the early discernible manifestation of PHPla.

Subcutaneous calcifications must be distinguished from other conditions. Ectopic calcifications are most frequently reported after subcutaneous fat necrosis following extravasation of calcium gluconate. It can be seen also in hyperparathyroidism, sarcoidosis, and dermatomyositis, and so forth. In addition, paternally inherited GNAS mutation may cause a rare disease termed progressive osseous heteroplasia 
$(\mathrm{POH})$ [7]. Subcutaneous ossifications in $\mathrm{POH}$ are accompanied with ossifications in cutaneous and in deep connective tissues including muscle. Fibrodysplasia ossificans progressive (FOP) is another condition manifesting heterotopic ossification [10]. Patients with FOP usually present with congenital malformations of the great toes, and the average age at onset of ossification was reported to be 5 years [10].

In conclusion, it should be emphasized that ectopic calcifications in neonates may indicate the systemic disorders.

\section{References}

[1] M. Bastepe and H. Jüppner, "Pseudohypoparathyroidism: new insights into an old disease," Endocrinology and Metabolism Clinics of North America, vol. 29, no. 3, pp. 569-589, 2000.

[2] L. S. Weinstein, P. V. Gejman, E. Friedman, et al., "Mutations of the $\mathrm{G}_{\mathrm{s}} \alpha$-subunit gene in Albright hereditary osteodystrophy detected by denaturing gradient gel electrophoresis," Proceedings of the National Academy of Sciences of the United States of America, vol. 87, no. 21, pp. 8287-8290, 1990.

[3] F. Albright, C. H. Burnett, P. H. Smith, and W. Parson, "Pseudohypoparathyroidism — an example of 'SeabrightBantam Syndrome," Endocrinology, vol. 30, pp. 922-932, 1942.

[4] S. J. Davies and H. E. Hughes, "Imprinting in Albright's hereditary osteodystrophy," Journal of Medical Genetics, vol. 30, no. 2, pp. 101-103, 1993.

[5] I. M. Gelfand, E. A. Eugster, and L. A. DiMeglio, "Presentation and clinical progression of pseudohypoparathyroidism with multi-hormone resistance and Albright hereditary osteodystrophy: a case series," Journal of Pediatrics, vol. 149, no. 6, pp. 877-880, 2006.

[6] M. Inokuchi, T. Hasegawa, M. Anzo, and N. Matsuo, "Standardized centile curves of body mass index for Japanese children and adolescents based on the 1978-1981 national survey data," Annals of Human Biology, vol. 33, no. 4, pp. 444453, 2006.

[7] N. S. Adegbite, M. Xu, F. S. Kaplan, E. M. Shore, and R. J. Pignolo, "Diagnostic and mutational spectrum of progressive osseous heteroplasia (POH) and other forms of GNASbased heterotopic ossification," American Journal of Medical Genetics, Part A, vol. 146, no. 14, pp. 1788-1796, 2008.

[8] S. Izraeli, A. Metzker, G. Horev, D. Karmi, P. Merlob, and Z. Farfel, "Albright hereditary osteodystrophy with hypothyroidism, normocalcemia, and normal Gs protein activity: a family presenting with congenital osteoma cutis," American Journal of Medical Genetics, vol. 43, no. 4, pp. 764-767, 1992.

[9] F. G. Riepe, W. Ahrens, N. Krone, et al., "Early manifestation of calcinosis cutis in pseudohypoparathyroidism type Ia associated with a novel mutation in the GNAS gene," European Journal of Endocrinology, vol. 152, no. 4, pp. 515-519, 2005.

[10] R. B. Cohen, G. V. Hahn, J. A. Tabas, et al., "The natural history of heterotopic ossification in patients who have fibrodysplasia ossificans progressiva. A study of forty-four patients," Journal of Bone and Joint Surgery. American, vol. 75, no. 2, pp. 215-219, 1993. 


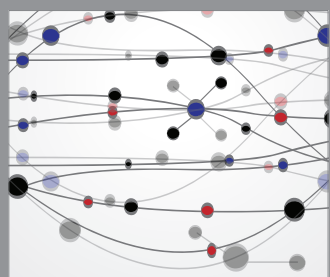

The Scientific World Journal
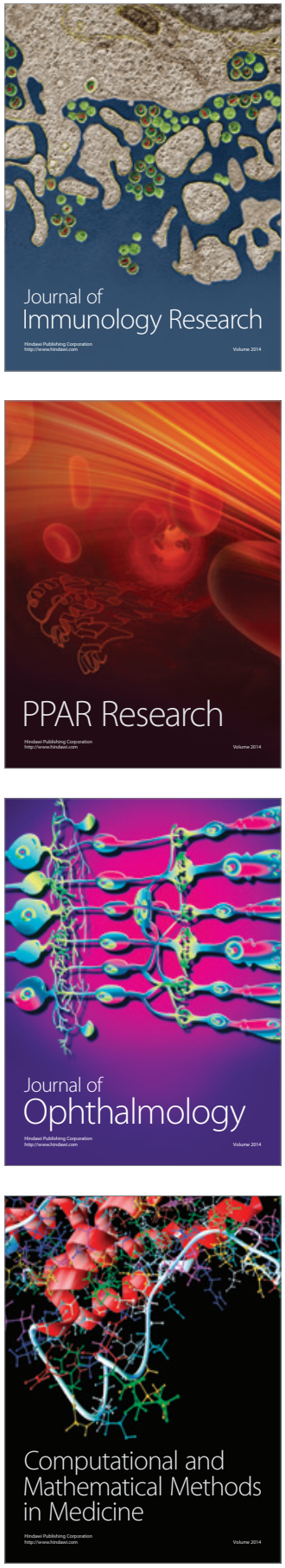

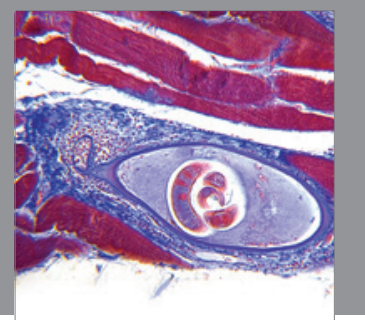

Gastroenterology

Research and Practice
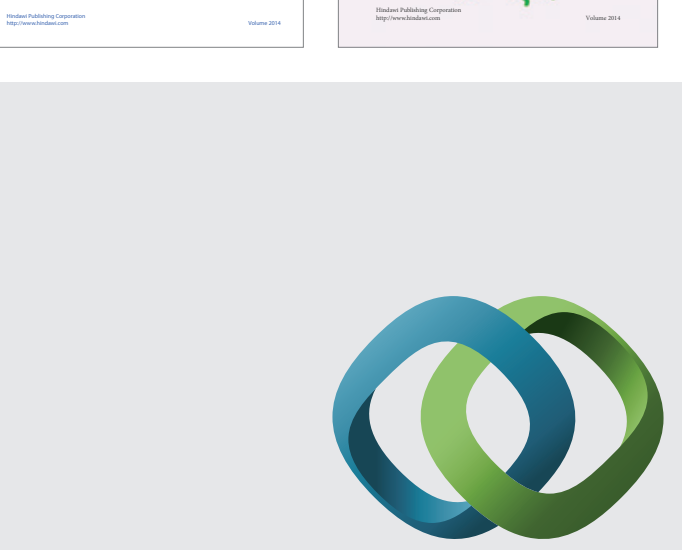

\section{Hindawi}

Submit your manuscripts at

http://www.hindawi.com
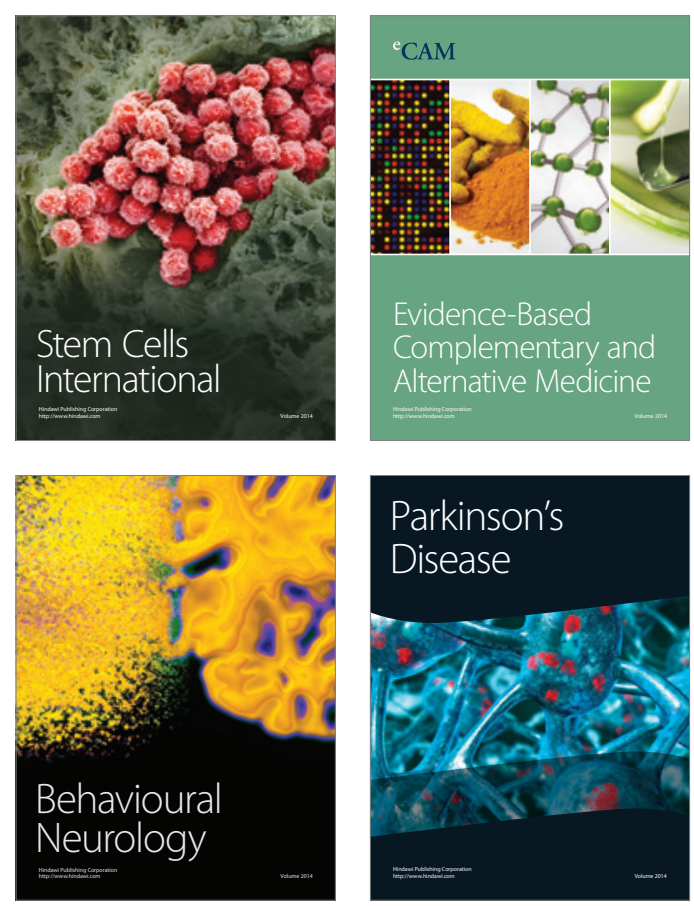

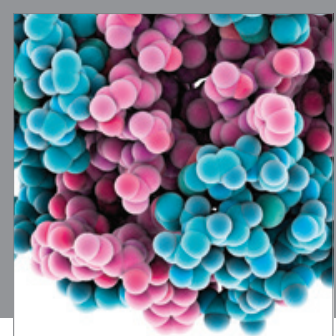

Journal of
Diabetes Research

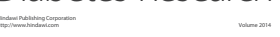

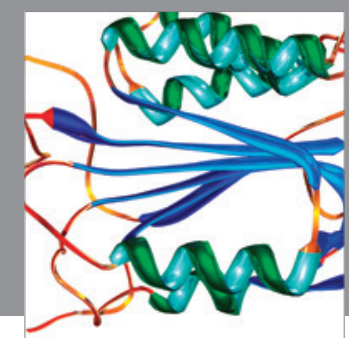

Disease Markers
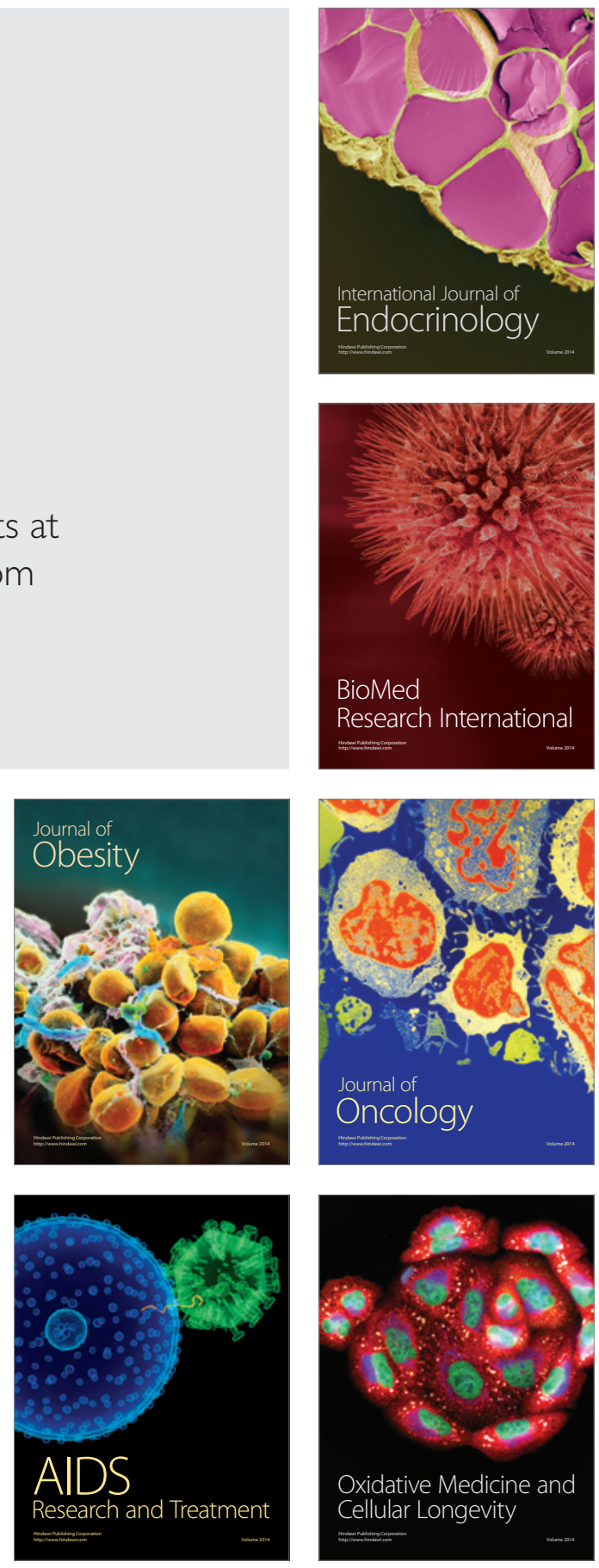